\title{
Pengaruh Experiential Marketing Terhadap Keputusan Pembelian Smartphone Xiaomi
}

\author{
Joni Budiarto ${ }^{1}$, Erminati Pancaningrum ${ }^{2}$ \\ STIE PGRI Dewantara Jombang
}

Korespondensi: ermi.sardjito72@gmail.com

\begin{abstract}
Abstrak
Penelitian ini dilatar belakangi oleh semakin besarnya nama perusahaan Xiaomi di dalam pasar smartphone khususnya di Indonesia. Experiential marketing adalah salah satu strategi pemasaran yang saat ini digunakan oleh banyak perusahaan termasuk Xiaomi. Strategi pemasaran yang tidak sekedar menawarkan produk saja, tetapi juga dengan melakukan pendekatan pengalaman dengan memerhatikan unsur (sense, feel, think, act dan relate). Penelitian ini dimaksudkan untuk mengetahui dan menganalisa pengaruh dari sense, feel, think, act dan relate terhadap keputusan pembelian smartphone Xiaomi. Populasi dalam penelitian ini adalah mahasiswa pengguna smartphone Xiaomi di STIE PGRI Dewantara Jombang. Sampel dalam penelitian ini berjumlah 85 mahasiswa yang diambil dengan teknik accidental sampling. Metode analisis data dalam penelitian ini menggunakan analisis linier berganda. Hasil penelitian ini menunjukkan bahwa variabel sense, feel, think, act dan relate berpengaruh positif signifikan terhadap keputusan pembelian. Kesimpulan dari penelitian ini adalah semakin kuat variabel experiential marketing (sense, feel, think, act dan relate) yang dirasakan konsumen terhadap smartphone Xiaomi, maka akan semakin baik pengaruhnya terhadap keputusan pembelian smartphone.
\end{abstract}

Kata Kunci: Experiential Marketing, Sense, Feel, Think, Act, Relate, Keputusan Pembelian

\begin{abstract}
This research is motivated by the increasing name of Xiaomi company in the smartphone market, especially in Indonesia. Experiential marketing is one of the marketing strategies currently used by many companies including Xiaomi. A marketing strategy that does not merely offer products, but also approaches the experience by paying attention to elements (sense, feel, think, act and relate). This study is intended to find out and analyze the influence of the sense, feel, think, act and relate to the purchasing decisions of Xiaomi smartphones. The population in this study were students of Xiaomi smartphone users at STIE PGRI Dewantara Jombang. The sample in this study amounted to 85 students taken by accidental sampling technique. Data analysis method in this study uses multiple linear analysis. The results of this study indicate that the variables sense, feel, think, act and relate have a significant positive effect on purchasing decisions. The conclusion of this study is that the stronger the experiential marketing variable (sense, feel, think, act and relate) that consumers feel towards Xiaomi smartphones, the better the effect will be on smartphone purchasing decisions.
\end{abstract}

Keywords: Experiential Marketing, Sense, Feel, Think, Act, Relate, Purchase Decision

\section{A. PENDAHULUAN}

Teknologi yang berkembang dan semakin modern berpengaruh secara luas terhadap berbagai aspek dalam kehidupan sehari-hari. Salah satunya adalah aspek komunikasi. Teknologi komunikasi adalah teknologi yang memiliki perkembangan cukup signifikan. Smartphone adalah salah satu dari beberapa teknologi di bidang komunikasi yang mengalami perkembangan sangat pesat. Hampir di setiap kalangan masyarakat telah mengenal smartphone. Organisasi bisnis saat ini juga telah memanfaatkan smartphone untuk mengenalkan produknya khususnya untuk pemasaran secara online (Febriyantoro, M. T., \& Arisandi, D. 2018), sehingga hal ini semakin membuat peran smartphone semakin penting bagi masyarakat.

Zaman yang semakin canggih memaksa produsen smartphone untuk mampu beradaptasi dengan perubahan lingkungan yang terjadi sebagai bentuk respon terhadap 
permintaan pasar yang semakin kompleks. Hal ini penting bagi kelangsungan perusahaan smartphone agar tetap mampu bersaing di pasar yang kompetitif. Salah satu merek smartphone yang sedang diminati saat ini adalah Xiaomi.

Xiaomi adalah salah satu vendor smartphone yang berasal dari Tiongkok dan saat ini telah memiliki banyak peminat di pasar smartphone salah satunya di Indonesia. Smartphone yang sedang digemari ini semakin menaiki peringkat dalam pasar yang kompetitif. Dikatakan dalam laporan riset pasar dari Canalys untuk kuartal 1 (satu) tahun 2018 bahwa Xiaomi berada di posisi kedua dari 5 (lima) vendor terbesar di pasaran Indonesia pada kuartal 1 tahun 2018.

Tabel 1 Market Analysis 2018

\begin{tabular}{cccccc}
\hline \multicolumn{5}{c}{ Indonesia Smartphone Market - Top 5 Vendors } \\
\hline Rank & Vendor & Q1 2017 & Q12018 & Growth & Share \\
\hline 1 & SAMSUNG & 2.0 million & 2.3 million & $17.2 \%$ & $25.5 \%$ \\
\hline 2 & XIAOMI & 107.000 & 1.7 million & $1455 \%$ & $18.3 \%$ \\
\hline 3 & OPPO & 1.5 million & 1.5 million & $5.2 \%$ & $16.8 \%$ \\
\hline 4 & VIVO & 510.000 & 600.000 & $16.7 \%$ & $6.5 \%$ \\
\hline 5 & SMARTFREN & 780.000 & 520.000 & $-34.0 \%$ & $5.6 \%$ \\
\hline
\end{tabular}

Sumber: Canalys estimates, Smartphone Analysis, May 2018

Dari tabel 1 (satu) di atas tercatat market share Xiaomi sebesar 18,3\% pada kuartal I (satu) tahun 2018, dengan mengalami kenaikan sebesar $1455 \%$. Sepanjang triwulan I (satu) tahun 2018 Xiaomi telah mengirimkan 1,7 juta unit perangkat smartphone-nya ke berbagai wilayah di Indonesia. Hal ini dapat dikatakan sebagai peningkatan pesat mengingat pada periode yang sama tahun lalu Xiaomi hanya mampu mengirimkan 107.000 perangkat smartphone.

Pada era kompetisi yang semakin ketat ini strategi pemasaran tradisonal yang berfokus pada kualitas dan kegunaan produk (feature and benefit) tidaklah cukup. Keberhasilan menciptakan nilai positif di benak konsumen adalah faktor yang penting dalam kesuksesan penjualan suatu produk (Rini, E. S, 2009). Penyampaian atau pengkomunikasian suatu produk dengan cara menyentuh sisi emosional konsumen perlu dilakukan. Salah satu konsep marketing modern yang sering digunakan oleh banyak perusahaan saat ini adalah experiential marketing. Experiential marketing merupakan konsep strategi pemasaran dengan melakukan pendekatan secara emosional kepada konsumennya dengan tujuan menciptakan pengalaman-pengalaman positif terhadap produk. Experiential marketing terdiri dari sense, feel, think, act dan relate (Schmitt, B. 1999). Dengan experiential marketing suatu perusahaan dapat memberikan pemahaman dan gambaran baru kepada konsumen berkaitan dengan produk sehingga timbul pengalaman positif terhadap produk dan merangsang konsumen untuk menggunakan produk tersebut.

Teori tentang experiential marketing telah banyak di kembangkan dalam beberapa penelitian seperti penelitian yang dilakukan oleh Bernd Schmitt yang berjudul Experiential Marketing (2010). Penelitian lainnya dilakukan oleh Balakumar dan Swarnalatha dengan konsep sikap konsumen yang dikaitkan dengan perilaku pembelian. Penelitian yang dilakukan oleh Dzakirah (2012) menjelaskan experiential marketing dari reputasi yang dimiliki jasa penyedia paket umrah mampu meningkatkan kepercayaan konsumen sehingga berpengaruh dalam keputusan pembelian. Penelitian lain yang dilakukan oleh Wicaksono (2015) yang mengaitkan experiential marketing dengan rumah 
makan Raminten. Rumah makan Raminten menerapkan elemen-elemen experiential marketing sehingga mampu memberikan konsumen pengalaman positif terhadap rumah makan tersebut.

Experiential marketing merupakan strategi yang juga diterapkan oleh Xiaomi. Xiaomi selalu meningkatkan kekuatan mereknya dengan memberikan pengalaman tentang produk smartphone-nya kepada konsumen melalui pendekatan emosional. Salah satunya, Xiaomi memberikan pengalaman kepada konsumennya melalui smartphone dengan memiliki kualitas bagus, fitur yang lengkap serta adanya spesifikasi yang dapat di pilih sehingga konsumen dapat menyesuaikan dengan gaya hidupnya. Selain itu Xiaomi juga menyediakan forum yang digunakan untuk berdiskusi bagi para pengguna smartphone Xiaomi sebagai media interaksi tentang berbagai informasi mengenai smartphone. Di dalam forum tersebut pengguna smartphone Xiaomi mampu berinteraksi satu sama lain dan saling bertukar pengalaman mulai dari permasalahan yang dihadapi saat menggunakan smartphone hingga solusi serta informasi-informasi tentang hal baru dari Xiaomi seperti adanya pembaruan sistem di waktu yang akan datang.

Dari latar belakang yang telah disampaikan diatas dengan didukung oleh penelitian terdahulu, maka rumusan masalah dalam penelitian ini adalah: Apakah experiential marketing berpengaruh terhadap keputusan pembelian. Hasil dari penelitian ini, diharapkan akan menjadi masukan serta bahan kajian bagi pihak-pihak terkait.

\section{B. TINJAUAN PUSTAKA}

\section{Experiential Marketing}

Kertajaya (2006) mendefinisikan experiential marketing sebagai sebuah konsep pemasaran yang tujuannya adalah membentuk loyalitas pelanggan dengan pendekatan emosi pelanggan dengan pengalaman-pengalaman positif serta memberikan suatu feeling yang positif terhadap produk dan jasa. Menurut Schmitt (1999) experiential marketing merupakan suatu proses penawaran produk dan jasa oleh pemasar kepada konsumen dengan perangsang emosi konsumen yang menghasilkan berbagai pengalaman bagi konsumen. Menurut Schmitt dalam experiential marketing terdapat experiential modules (SEMs) mendeskripsikan lima tipe pengalaman pelanggan yang merupakan dasar dari experiential marketing. Kelima tipe tersebut adalah: 1) sense, 2) feel, 3) think, 4) act, dan 5) relate.

1. Sense (Panca Indera). Tipe pengalaman yang bertujuan untuk menciptakan pengalaman kepada konsumen melalui panca indera. Merupakan pengalaman yang dirasakan konsumen terhadap Xiaomi melalui panca indera. Sense dapat di ukur dengan indikator (Schmitt dalam Hamzah):

a. Penglihatan, Pengalaman yang muncul berkaitan dengan pandangan konsumen terhadap fisik dari produk smartphone Xiaomi meliputi bentuk, warna dan keadaan fisik lainnya.

b. Pendengaran, Pengalaman yang muncul berkaitan dengan kemampuan produk Xiaomi dalam aspek pendengaran seperti memberikan kualitas atau karakter suara dari smartphone Xiaomi.

c. Peraba, Pengalaman yang muncul berkaitan dengan sentuhan, perasaan konsumen saat memegang smartphone Xiaomi.

2. Feel (Perasaan). Merupakan pengalaman yang ditujukan pada perasaan serta emosi konsumen dan bertujuan mempengaruhi pengalaman mulai dari suasana hati sampai dengan emosi yang kuat terhadap kenangan dan kebanggaan pada produk smartphone Xiaomi. Feel dapat di ukur dengan indikator (Schmitt dalam Hamzah): 
a. Kebanggaan atau kesenangan. Pengalaman yang dirasakan konsumen ketika menggunakan produk Xiaomi yang berhubungan dengan perasaan senang atau bangga dalam benak konsumen.

b. Hubungan konsumen dengan produk. Kondisi yang menghubungkan produk Xiaomi dengan konsumen dan dapat mempengaruhi perasaan konsumen terhadap produk Xiaomi.

3. Think (Pikiran). Merupakan tipe pengalaman dengan tujuan menciptakan sebuah kognitif, pemecahan masalah yang mampu mengajak konsumen untuk berfikir secara kreatif dan merupakan kemampuan perusahaan untuk membangkitkan keterlibatan konsumen melalui rasa ingin tahu dan ketertarikan konsumen tentang produk smartphone Xiaomi. Think dapat di ukur dengan indikator (Schmitt dalam Hamzah):

a. Surprise. Merupakan dasar penting untuk memikat konsumen untuk berfikir sebagai akibat ketika konsumen merasa mendapatkan sesuatu yang melebihi ekspektasi sehingga timbul kepuasan.

b. Intriguing. Intriguing membangkitkan rasa ingin tahu konsumen dengan melibatkan konsumen secara langsung namun tergantung pada tingkat pengetahuan, kesukaan, dan pengalaman konsumen itu sendiri.

c. Provocation. Provocation mampu menimbulkan diskusi atau perdebatan. Pemasar dapat menggunakan strategi ini dengan melakukan promosi yang unik dengan tujuan mempengaruhi konsumen sehingga akhirnya memutuskan untuk melakukan pembelian.

4. Act (Tindakan). Merupakan jenis pengalaman yang bertujuan mempengaruhi perilaku, gaya hidup dan interaksi dengan konsumen. Act mengarah pada kemampuan perusahaan Xiaomi untuk mempengaruhi perilaku, gaya hidup dan interaksi konsumen melalui produknya. Act dapat di ukur dengan indikator (Schmitt dalam Hamzah):

a. Varian atau keaneka ragaman. Bentuk atau pelayanan yang diberikan oleh Xiaomi kepada konsumennya berupa kelonggaran untuk memilih berbagai produk yang sesuai dengan keinginan konsumen.

b. Gaya hidup. Pengalaman yang di berikan oleh Xiaomi sebagai gambaran dari gaya hidup konsumen.

c. Interaksi. Pengalaman yang berkaitan dengan tindakan atau aktivitas dari Xiaomi untuk menunjukkan pelayanannya terhadap konsumen.

5. Relate (Hubungan). Merupakan pengalaman yang digunakan untuk mempengaruhi konsumen dengan menggabungkan seluruh aspek (sense, feel, think dan $a c t$ ) dan menitik beratkan pada penciptaan presepsi positif di mata konsumen. Relate memberikan pengalaman konsumen yang terkait dengan sense, feel, think, dan act dalam mengaitkan produk smartphone Xiaomi dengan dirinya sendiri. Relate dapat di ukur dengan indikator (Schmitt dalam Hamzah):

a. Hubungan dengan orang lain. Pengalaman konsumen dengan Xiaomi yang timbul dan menciptakan hubungan dengan konsumen lain.

b. Komunitas. Bentuk keterlibatan konsumen dengan pengembang produk Xiaomi dalam sebuah kelompok diskusi yang disediakan oleh Xiaomi sebagai timbal balik atau masukan untuk Xiaomi.

\section{Keputusan Pembelian}

Keputusan pembelian merupakan kegiatan individu yang secara langsung terlibat dalam pengambilan keputusan untuk melakukan pembelian terhadap produk yang 
ditawarkan oleh penjual. Konsumen akan melalui tahapan-tahapan sebelum menentukan untuk membeli smartphone Xiaomi. indikator dari keputusan pembelian yaitu (Kotler, 2009):

1. Pengenalan Masalah, Tahap dimana konsumen menyadari akan kebutuhannya terhadap suatu produk dari smartphone Xiaomi.

2. Pencarian Informasi, Kegiatan konsumen dalam mengumpulkan informasi tentang produk Xiaomi sebagai pemenuhan rasa ingin tahu konsumen terhadap produk Xiaomi.

3. Evaluasi Alternatif, Konsumen menentukan alternatif pilihan dari informasi yang didapatkan tentang produk Xiaomi sebagai pertimbangan.

4. Keputusan Pembelian, Keputusan konsumen untuk melakukan pembelian produk Xiaomi.

\section{Kerangka Konseptual Penelitian}

Berdasarkan tinjauan pustaka yang telah disampaikan diatas, maka kerangka penelitian ini adalah:

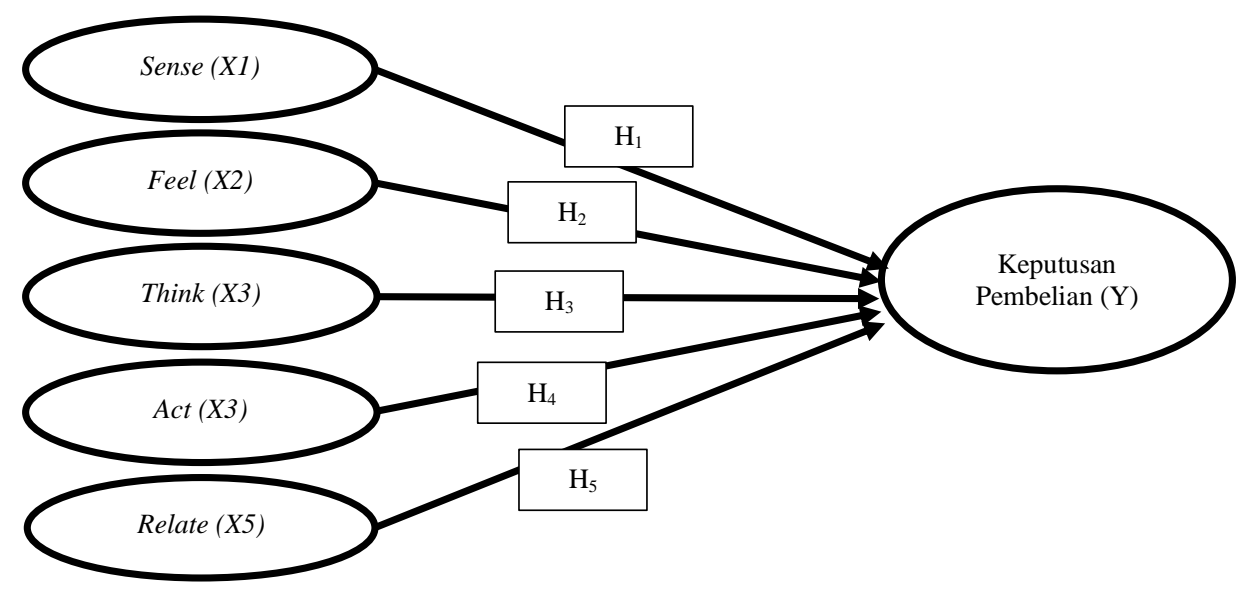

Gambar 1: Kerangka Penelitian

\section{Hipotesis}

Penelitian yang dilakukan oleh Artika (2015) menunjukkan hasil bahwa elemen experiential marketing yang terdiri dari sense, feel, think, act dan relate memberikan pengaruh positif dan signifikan terhadap keputusan pembelian. Untuk itu, hipotesis pertama dalam penelitian ini adalah:

$\mathrm{H}_{1}$ : Semakin kuat sense maka semakin baik pengaruhnya terhadap keputusan pembelian smartphone Xiaomi pada mahasiswa STIE PGRI Dewantara Jombang.

Penelitian yang dilakukan oleh Dzakirah (2012) menunjukkan bahwa variabel feel berpengaruh positif dan signifikan terhadap keputusan pembelian konsumen. Feel yang dirasakan konsumen terhadap penyedia jasa paket umroh mampu meningkatkan keputusan pembelian konsumen. Untuk itu, hipotesis kedua dalam penelitian ini adalah:

$\mathrm{H}_{2}$ : Semakin kuat feel maka semakin baik pengaruhnya terhadap keputusan pembelian smartphone Xiaomi pada mahasiswa STIE PGRI Dewantara Jombang.

Penelitian yang dilakukan oleh Northee (2015) hasil menunjukkan bahwa variabel think berpengaruh positif dan signifikan terhadap keputusan pembelian mobil Suzuki. Dengan fitur serta kualitas yang diberikan oleh Suzuki mampu memberikan kejutan untuk konsumen sehingga memberikan pengalaman yang positif terhadap keputusan pembelian. Untuk itu, hipotesis ketiga dalam penelitian ini adalah: 
$\mathrm{H}_{3}$ : Semakin kuat think maka semakin baik pengaruhnya terhadap keputusan pembelian smartphone Xiaomi pada mahasiswa STIE PGRI Dewantara Jombang.

Penelitian yang dilakukan Maulina et al (2014) menunjukkan bahwa act berpengaruh positif dan signifikan terhadap keputusan pembelian pecel lele di kota Padang. Tersedianya varian menu yang ada pecel lele Lela memberikan kebebasan kepada konsumen untuk memilih menu sesuai selera. Untuk itu, hipotesis keempat dalam penelitian ini adalah:

$\mathrm{H}_{4}$ : Semakin kuat act maka semakin baik pengaruhnya terhadap keputusan pembelian smartphone Xiaomi pada mahasiswa STIE PGRI Dewantara Jombang.

Penelitian yang dilakukan Khaerudin (2015) hasil menunjukkan bahwa relate berpengaruh positif dan signifikan terhadap keputusan untuk mengunjungi tempat wisata Agrowisata Kaligua. Adanya pengalaman yang positif kepada setiap pengunjung yang melakukan kunjungan wisata serta menjaga erat hubungan antara pengelola serta hubungan antara pengunjung denga pegawai. Untuk itu, hipotesis kelima dalam penelitian ini adalah:

$\mathrm{H}_{5}$ : Semakin kuat relate maka semakin baik pengaruhnya terhadap keputusan pembelian smartphone Xiaomi pada mahasiswa STIE PGRI Dewantara Jombang.

\section{METODE PENELITIAN}

Penelitian ini berjenis explanatory research, yang menjelaskan hubungan kausal antara variabel penelitian dan menguji hipotesis yang telah dirumuskan sebelumnya (Singarimbun dan Masri, 2006) dengan pendekatan kuantitatif. Populasi pada penelitian ini adalah mahasiswa aktif STIE PGRI Dewantara Jombang yang menggunakan smartphone Xiaomi, sedangkan sampel yang terlibat dalam penelitian ini sebanyak 85 responden yang diambil dengan teknik accidental sampling.

Data yang digunakan adalah data primer yang didapat melalui kuisioner yang disebar kepada responden yang terkait variabel independen yaitu Sense $\left(\mathrm{X}_{1}\right)$, Feel $\left(\mathrm{X}_{2}\right)$, Think $\left(\mathrm{X}_{3}\right)$, Act $\left(\mathrm{X}_{4}\right)$, Relate $\left(\mathrm{X}_{5}\right)$ dan satu variabel dependen yaitu Keputusan Pembelian (Y). Metode analisis data yang digunakan adalah Regresi Linier Berganda dengan alat analisis SPSS V.25 serta melakukan uji hipotesis berupa uji instrumen, uji asumsi klasik dan uji hipotesis.

\section{HASIL PENELITIAN DAN PEMBAHASAN \\ 1. Deskripsi Responden}

Dari hasil pengolahan data, diketahui bahwa deskripsi responden pengguna smartphone Xiaomi adalah sebagai berikut: sebanyak 67 berasal dari program studi Manajemen dan 18 berasal dari program studi Akuntansi. Sebanyak 85 responden terdiri dari 41 laki-laki dan 44 perempuan. Sebanyak 41 responden bergabng dengan komunitas Mi-fans dan 39 tidak bergabung dengan komunitas, sisanya sebanyak 5 responden tidak tahu tentang komunitas tersebut.

\section{Pengukuran Validitas dan Reliabilitas}

Sebuah item dikatakan valid jika r-hitung > r-tabel, artinya bila harga korelasi setiap item instrumen di bawah 0.30, maka dapat dikatakan bahwa butir instrumen tersebut tidak valid, sehingga harus diperbaiki atau dibuang (Sugiyono, 2012). Sebuah instrumen dinyatakan reliabel atau handal jika koefisien alpha cronbach > 0,6 (Sugiyono, 2012). Dari hasil pengolahan data diketahui bahwa hasil pengukuran validiatas dan reliabilitas variabel tampak sebagai berikut: 
Tabel 2 Hasil Pengukuran Validitas dan Reliabilitas

\begin{tabular}{|c|c|c|c|}
\hline Variabel & $\begin{array}{c}\text { Item } \\
\text { Pertanyaan }\end{array}$ & $\begin{array}{c}\mathbf{r} \\
\text { hitung }\end{array}$ & $\begin{array}{c}\text { Alpha } \\
\text { Cronbach }\end{array}$ \\
\hline \multirow{4}{*}{ Sense (X1) } & $\mathrm{X} 1.1$ & 0,650 & \multirow{4}{*}{0,789} \\
\hline & X1.2 & 0,820 & \\
\hline & X1.3 & 0,870 & \\
\hline & $\mathrm{X} 1.4$ & 0,801 & \\
\hline \multirow{3}{*}{ Feel (X2) } & $\mathrm{X} 2.1$ & 0,761 & \multirow{3}{*}{0,658} \\
\hline & $\mathrm{X} 2.2$ & 0,845 & \\
\hline & X2.3 & 0,714 & \\
\hline \multirow{4}{*}{ Think (X3) } & X3.1 & 0,488 & \multirow{4}{*}{0,669} \\
\hline & X3.2 & 0,721 & \\
\hline & X3.3 & 0,832 & \\
\hline & X3.4 & 0,780 & \\
\hline \multirow{3}{*}{ Act (X4) } & $\mathrm{X} 4.1$ & 0,694 & \multirow{3}{*}{0,639} \\
\hline & $\mathrm{X} 4.2$ & 0,810 & \\
\hline & $\mathrm{X} 4.3$ & 0,780 & \\
\hline \multirow{3}{*}{ Relate (X5) } & X5.1 & 0,877 & \multirow{3}{*}{0,855} \\
\hline & X5.2 & 0,911 & \\
\hline & X5.3 & 0,893 & \\
\hline \multirow{5}{*}{$\begin{array}{c}\text { Keputusan } \\
\text { Pembelian (Y) }\end{array}$} & Y1.1 & 0,548 & \multirow{5}{*}{0,648} \\
\hline & Y1.2 & 0,801 & \\
\hline & Y1.3 & 0,774 & \\
\hline & Y1.4 & 0,500 & \\
\hline & Y1.5 & 0,584 & \\
\hline
\end{tabular}

Sumber: Data diolah, 2018

Pada tabel 2 (dua) diatas, dapat dilihat bahwa nilai r-hitung setiap variabel seluruhnya lebih besar dari 0,30 maka dapat disimpulkan semua variabel dikatakan valid. Pada kolom alpha cronbach dapat dilihat bahwa setiap nilai dari masing-masing variabel menunjukkan nilai yang lebih dari 0,60, maka dapat dikatakan bahwa semua instrumen pada penelitian ini dinyatakan reliabel.

\section{Hasil Perhitungan Regresi Berganda}

Berdasarkan data yang telah dikumpulkan dengan menggunakan program SPSS. Maka diperoleh hasil olahan seperti tabel 3 (tiga) berikut:

Tabel 3: Hasil Uji Regresi Linier Berganda

\begin{tabular}{|c|c|c|c|c|}
\hline Variabel & $\begin{array}{c}\text { Koefisien } \\
\text { Regresi }\end{array}$ & t Hitung & P-Value & Signifikasi \\
\hline Sense & 0,297 & 2,569 & 0,012 & Signifikan \\
\hline Feel & 0,363 & 3,356 & 0,001 & Signifikan \\
\hline Think & 0,292 & 3,013 & 0,003 & Signifikan \\
\hline Act & 0,239 & 2,105 & 0,038 & Signifikan \\
\hline Relate & 0,157 & 2,167 & 0,033 & Signifikan \\
\hline $\begin{array}{l}\text { Konstanta } \\
\text { R }\end{array}$ & $: 2,259$ & & F Hitung & $: 18,729$ \\
R Square & $: 0,736^{\mathrm{a}}$ & & Sig. & $: 0,000^{\mathrm{b}}$ \\
\hline
\end{tabular}

Berdasarkan hasil analisa regresi yang disajikan dalam tabel 3 (tiga) diatas maka didapatkan persamaan sebagai berikut:

$$
\hat{Y}=2,259+0,297 X_{1}+0,363 X_{2}+0,292 X_{3}+0,239 X_{4}+0,157 X_{5}
$$

Dari persamaan diatas diketahui bahwa koefisien regresi seluruh variabel bernilai positif, maka dapat diartikan bahwa semakin semakin kuat seluruh variabel yang meliputi variabel sense $\left(X_{1}\right)$, feel $\left(\mathrm{X}_{2}\right)$, think $\left(\mathrm{X}_{3}\right)$, act $\left(\mathrm{X}_{4}\right)$, relate $\left(\mathrm{X}_{5}\right)$ akan semakin baik 
pengaruhnya terhadap keputusan pembelian. Maka dengan demikian dapat disimpulkan bahwa seluruh hipotesis yang diajukan dapat diterima.

\section{Uji Koefisien Determinasi $\left(R^{2}\right)$}

Uji koefisien determinasi digunakan untuk mengetahui seberapa besar varian dari variabel dependen dapat dijelaskan oleh variabel independen (Ghozali, 2013). Berdasarkan tabel 5 di atas diperoleh nilai $\mathrm{R}^{2}$ sebesar 0,542. yang dapat disimpulkan bahwa $54,2 \%$ variasi keputusan pembelian dijelaskan oleh faktor experiential marketing yang terdiri dari sense, feel, think, act dan relate, sementara sisanya 45,8\% dijelaskan oleh faktor lain yang tidak diteliti dalam penelitian ini.

Dari hasil pembahasan diatas semakin menguatkan penelitian yang dilakukan oleh Artika (2015), yang menemukan bahwa elemen experiential marketing yang terdiri dari sense, feel, think, act dan relate mampu memberikan peningkatan keputusan pembelian mobil Suzuki. Hal ini juga selaras dengan penelitian yang dilakukan oleh Wicaksono (2015), peneliti menemukan bahwa feel berkontribusi terhadap keputusan pembelian di rumah makan Raminten Yogyakarta. Konsumen merasakan pengalaman feel melalui service yang bagus seperti keramahan pelayanan yang baik sebagai pengalaman positif yang berdampak terhadap keputusan pembelian konsumen terhadap rumah makan tersebut.

Khaerudin (2015) yang meneliti tentang peran experiential marketing terhadap keputusan mengunjungi tempat wisata, juga menyatakan bahwa bahwa relate mampu memberikan dorongan terhadap keputusan konsumen untuk mengunjungi tempat wisata Agrowisata Kaligua. Agrowisata Kaligua mampu memberikan pengalaman yang positif kepada setiap pengunjung yang melakukan kunjungan wisata serta menjaga erat hubungan antara pengelola serta hubungan antara pengunjung denga pegawai.

\section{E. PENUTUP}

Berdasarkan hasil analisis dan pembahasan yang telah dilakukan dapat disimpulkan bahwa seluruh variabel yang meliputi variabel sense $\left(X_{1}\right)$, feel $\left(\mathrm{X}_{2}\right)$, think $\left(\mathrm{X}_{3}\right)$, act $\left(\mathrm{X}_{4}\right)$, relate $\left(\mathrm{X}_{5}\right)$ berpengaruh positif dan signifikan terhadap keputusan pembelian $(\mathrm{Y})$. Oleh karena itu disarankan kepada pihak manajemen smartphone Xiaomi hendaknya memperhatikan dimensi-dimensi experiential marketing meliputi sense, feel, think, act dan relate karena terbukti aspek-aspek ini memiliki kontribusi yang baik terhadap keputusan pembelian. Pada item "saya bergabung ke dalam komunitas Mi-Fans karena tertarik dengan komunitas tersebut" mendapat nilai terendah yaitu 3,1. Xiaomi harus lebih memperhatikan komunitas Mi-fans agar lebih dikenal konsumennya dengan mengadakan event misalnya seperti melakukan challenge dan giveaway.

Bagi peneliti selanjutnya yang tertarik untuk mengembangkan hasil penelitian ini, dapat mengembangkan model penelitian agar lebih baik dengan menambahkan variabel lain seperti emotional marketing.

\section{DAFTAR PUSTAKA}

Andreani, F. (2007), Experiential Marketing (Sebuah Pendekatan Pemasaran), Jurnal Manajemen Pemasaran, Erlangga. Jakarta.

Andreani. F. (2007). Experiental Marketing. Jurnal Manajemen Pemasaran.Vol. 2. No. 1. p. 18

Atina Arlia Wardani (2011). Experiential Marketing. Jurnal manajemen pemasaran, Badan penerbit Universitas Diponegoro, Semarang. 
Dzakirah N (2012). Analisis Pengaruh Experiential Marketing Terhadap Keputusan Pembelian (Studi pada Pembelian Paket Umrah di PT Saibah). Skripsi,

Febriyantoro, M. T., \& Arisandi, D. (2018). Pemanfaatan Digital Marketing Bagi Usaha Mikro, Kecil Dan Menengah Pada Era Masyarakat Ekonomi Asean. JMD: Jurnal Riset Manajemen \& Bisnis Dewantara, 1(2), 61-76.

Ferdinand, Agusty. (2006). Metode Penelitian Manajemen (Pedoman Penelitian untuk Penulisan Skripsi, Tesis, Disertasi Ilmu Manajemen). Semarang: Badan Penerbit Universitas Diponegoro.

Hamzah, Amir (2007), Analisis Experiential Marketing, Emotional Branding dan Brand Trust Terhadap Loyalitas Merek Mentari, USAHAWAN No. 06 Th XXXVI Juni p. 22-8.

Hermawan Kartajaya. (2002). Hermawan Kartajaya On Marketing. Jakarta: PT. Gramedia Pustaka Utama Hermawan Kartajaya. 2004. Positioning, Diferensiasi, dan Brand. Jakarta: PT. Gramedia Pustaka Utama.

https://tekno.kompas.com/read/2018/05/15/08274587/survei-canalys-xiaomi-vendorponsel-terbesar-ke-2-di-indonesia. [Accessed 5 April 2018]

Kartajaya, Hermawan, (2007) " ciptakan great Experience" swa sembada, No. 15/ XXIII 12- 25 Juli.

Kartajaya, Hermawan. (2006), Hermawan Kartajaya on Marketing. Jakarta : Gramedia Pustaka Utama.

Kotler, P \& Amstrong, J. (2003). Dasar-dasar pemasaran. (9th ed.). Jakarta: PT. Index Kelompok Gramedia

Kotler, P. (2000). Manajemen Pemasaran di Indonesia. Salemba. Jakarta

Kotler, P., dan Amstrong, J. (2003). Dasar-dasar Pemasaran. Edisi kesembilan. PT Index Kelompok Gramedia. Jakarta.

Kotler, Philip (2009). Manajemen Pemasaran. Jakarta: PT.Indeks

Kotler, Philip. \& Kevin, Keller. (2009). Manajemen Pemasaran. Edisi Ketiga Belas Jilid Satu, Penerbit PT Gelora Aksara Pratama.

Kumala Dkk. (2011). Pengaruh Experiential Marketing Terhadap Kepuasan Pelanggan. (Survei Pada Pelanggan KFC Warga JL. Jendral Basuki Rachmad RW. 02 Kelurahan Kauman Kecamatan Klojen Kota Malang). Fakultas Ilmu Administrasi Universitas Brawijaya Malang.

Kustini. (2007). Penerapan Experiential Marketing. Jurnal Riset Ekonomi Bisnis.

Rini, E. (2009) "Menciptakan Pengalaman Konsumen dengan Experiential Marketing." Jurnal Manajemen Bisnis, Vol. 2, No. 2, h. 15-20.

Rini, E. S. (2009). Menciptakan pengalaman konsumen dengan experiential marketing.

Schmitt, B. (1999). Experiential marketing. Journal of marketing management, 15(1-3), 53-67.

Schmitt, B. (2009), Experiential Marketing: How to Get Your Customers to Sense, Feel, Think, Act, and Relate to Your Company and Branda. The Free Press. New York.

Schmitt, Bernd (1999), Experiential Marketing. The Free Press Now York.

Sugiyono, (2007), Metode Penelitian Pendidikan, Bandung: Alfabeta.

Wardani A.A. (2011). Analisis Pengaruh Experiential Marketing Terhadap Keputusan Pembelian (Studi pada Derajat Celcius). Skripsi, Program Sarjana Universitas Diponegoro, Semarang.

Wicaksono (2015). Pengaruh Experiential Marketing Terhadap Keputusan Pembelian di Rumah Makan Raminten di Yogyakarta. Universitas Muhammadiyah. Purworejo. 
Yulianto, Ade. (2010). "Dampak Experiential Marketing Terhadap Loyalitas Pelanggan Resort Kampoeng Legok Lembang”. Skripsi, Jurusan Manajemen Fakultas Ekonomi Universitas Komputer Indonesia.

Yuniati T. dan Soecharno A.D. (2015) Analisis Pengaruh Elemen Experiential Marketing Terhadap Keputusan Pembelian Mobil Suzuki Umc Surabaya. Skripsi, program sarjana Sekolah Tinggi Ilmu Ekonomi Indonesia, Surabaya 